\title{
Funding the new biologics - Public policy issues in drug formulary decision making
}

\author{
Steven Lewis MA
}

$\mathrm{S}$ Lewis. Public policy issues in drug formulary decision making. Can J Gastroenterol 2002;16(12):869-872

One function of drug formularies is to allow health care providers to exert some control over spending. Decisions about whether to include a given medication in a formulary are based on estimates of its costs and effectiveness, relative to other treatment strategies. These decisions are made from a societal perspective, as opposed to that of individual patients, which sometimes results in conflicts. The clinical response to a medication often varies widely among subjects, which means that a small subgroup of patients might benefit dramatically, while others with the same disease do not. The result would be that a drug might appear not to be cost effective in an economic analysis, even though it is of proven value for some patients. New and innovative medications are assessed according to high standards of cost effectiveness, even though established treatments are wasteful of valuable health care resources. Moreover, quality-adjusted life-years (QALYs) discriminate against certain patient groups, including those with diseases that are associated with a high morbidity but a low mortality. Such patients often incur high indirect costs, including loss of employment income and costs incurred by family caregivers that QALYs do not reflect. Therefore, even though QALYs are transparent and widely applicable, they are not necessarily appropriate in the evaluation of a particular therapeutic intervention. A new paradigm should be developed for evaluating emerging therapies. An example would be a risk-sharing approach, whereby the pharmaceutical industry and public insurers share in the costs and rewards of introducing new treatments. This would have implications for the prices charged for new medications.

Key Words: Drug formulary; Infliximab; Pharmacoeconomics; QALY

\section{Enjeux des politiques gouvernementales rela- tives à la prise de décision concernant les listes de médicaments}

RÉSUMÉ : Les listes de médicaments servent notamment à permettre aux fournisseurs de soins de santé d'exercer un certain contrôle des dépenses. Les décisions concernant l'inclusion ou non d'un médicament donné dans la liste reposent sur des estimations du coût et de l'efficacité du médicament en cause par rapport à d'autres stratégies de traitement. Ces décisions faites dans une perspective de société, et non de patients individuels, suscitent parfois des conflits. Souvent, la réponse clinique à un médicament varie considérablement entre sujets, par exemple lorsqu'un petit groupe de patients peut en tirer des avantages notables, alors que d'autres personnes atteintes de la même maladie n'en obtiennent aucun bienfait. Ce médicament pourrait, dans une analyse économique, présenter un rapport coût-efficacité inintéressant même s'il procure des bienfaits à certains patients. Les nouveaux médicaments novateurs sont évalués selon des critères rigoureux de rapport coût-efficacité, même si les traitements établis entraînent le gaspillage de ressources de soins de santé. De plus, le recours à des valeurs comme les années-personnes sans invalidité désavantage certains groupes de patients, notamment ceux qui souffrent d'une maladie à morbidité élevée, mais à mortalité faible. Pour ces patients, les coûts indirects sont souvent élevés, notamment par la perte de revenus d'emploi et les coûts supportés par les aidants membres de la famille, dont les années-personnes sans invalidité ne tiennent pas compte. Par conséquent, bien que les valeurs « années-personnes sans invalidité » soient transparentes et qu'elles s'appliquent largement, elles ne sont pas nécessairement appropriées pour évaluer une intervention thérapeutique donnée. Il faudrait élaborer un nouveau modèle pour évaluer les nouvelles thérapies. Par exemple, une démarche à risques partagés, selon laquelle l'industrie pharmaceutique et les assureurs gouvernementaux partagent les coûts et les retombées positives de la présentation de nouveaux traitements, ce qui aurait des conséquences sur le prix des nouveaux médicaments.

Presented at a workshop held at the University of Calgary, September 24, 2002. The workshop was supported by an unrestricted grant from Schering Pharmaceuticals, Pointe-Claire, Quebec

Access Consulting Ltd, Saskatoon, Saskatchewan, and Centre for Health and Policy Studies, University of Calgary, Calgary, Alberta

Correspondence and reprints: S Lewis, Access Consulting Ltd, 211 Fourth Avenue South, Saskatoon, Saskatchewan S7K 1N1.

Telephone 306-343-1007, fax 306-343-1071, e-mail Steven.Lewis@shaw.ca 
$\mathrm{D}$ rug formularies are used by both public and private drug plans to exert some control over quality, utilization and costs. Whether a medication is included in or excluded from a formulary can have significant consequences for not only the company and the insurance plan, but also for individuals with a particular disorder. Even though formulary decisions in private and public insurance markets are based on some of the same criteria, public agencies must recognize an additional set of obligations and accountabilities. The present paper will outline some of the issues that determine formulary decisions, and particularly the special role of the provincial drug formulary in the fulfillment of the public interest.

\section{THE 'BLUNT INSTRUMENT' DILEMMA}

Medical interventions, even when optimally applied, often have different outcomes in various populations. Drugs that are effective for some patients may inexplicably be of little value for others. A large clinical trial that shows a modest overall effect might include a substantial number of patients who benefit to a far greater degree. Conversely, drugs that are clinically effective in general may be ineffective and even harmful in some cases. The individual patient is the focus of clinical encounters, whereas public policy decision-makers are concerned with large numbers of patients or even the entire population. It is not always possible to reconcile the conflicting needs of the patient with those of society in general. Hence the need for balance.

In the case of health care, the stakes are often very high and the costs are asymmetrically borne. A public policy decision can have dramatic consequences for the health (and even the life) of an individual patient. On the other hand, health care costs are widely distributed across society and it is literally impossible to determine the precise effects of a given resource allocation decision on the population at large. This fact at least partly accounts for the tendency for prosperous societies to allow considerable latitude for individual judgments provided that they are based on a coherent rationale.

Formularies are comparatively blunt instruments for governing clinical practice. Their decisions are usually binary: a drug is either included or excluded. If formulary committees were to adopt intermediate positions routinely, and allow appeals, special rulings, et cetera, they could potentially invite an unsustainable burden of review and assessment. For this reason, they rely on a number of decision-making criteria that collectively define, if only implicitly, their notion of fairness.

A key assumption underlying formulary decisions is that approved drugs will be properly prescribed and administered. This is entirely reasonable - one wonders how a formulary, in calculating the cost effectiveness of a medication could accurately incorporate the effects of suboptimal prescribing practices and patient noncompliance - but there is a huge body of evidence that demonstrates that this assumption is overly optimistic (1). In clinical practice, examples of the inappropriate use of medications abound: antibiotics for viral infections (2), mood modifiers (3) and polypharmacy among elderly patients (4). Expensive drugs are often prescribed instead of equally effective and cheaper alternatives. In short, 'real world' practice often deviates from the findings of clinical trials, accounting for the wellknown difference between efficacy and effectiveness.

\section{THE DISTRIBUTIVE JUSTICE DILEMMA}

While formularies may be blunt instruments whose evaluative criteria may unavoidably be based on unattainable standards of practice, they may nonetheless be the best that can be achieved. Given the general preference for a patient-centred health care system that is able to respond, within reason, to individual circumstances, policy dilemmas arise when considering medications that either help a relatively small number of patients or whose clinical benefits are highly variable. What is the appropriate comparator in such instances? For instance, should estimates of cost effectiveness be based on the average effects on a large population of patients or on the subgroup that enjoy far greater benefits? Is it possible to create reasonable and transparent decision rules to define a patient population for which use of the medication would be cost effective? Should new products be measured against the benchmark of ideal standards or of actual clinical practice in the community?

In principle, a just health care system provides all patients an equal opportunity to have their needs met, within the limits of scientific and medical knowledge and the capacity to intervene. This means that the decision to treat a patient should be dictated by the degree of health impairment and disability, rather than by the cost of treatment (5). Adoption of a completely utilitarian system - one based on providing the greatest good, as measured by quality-adjusted life years (QALYs), disability-adjusted life years or some other parameter, for the greatest number of people - would involve a massive reallocation of resources, both away from health care towards other sectors, and within the health care system itself.

When nations are compared, however, there is no correlation between key indicators of health care status, such as life expectancy or infant mortality rate, and per capita level of health care spending beyond approximately US $\$ 500$ to US\$1000 per year (Canada spends about US\$2200 per year) (6). Costs per QALY vary enormously depending on the nature of the condition and the available therapies. Yet it is obvious that our society does not adhere to a strictly utilitarian calculus. Taxpayers are content to allocate massive resources to the treatment of patients who are at the end of their lives, when the prospects of full recovery are virtually nonexistent. There is no public opposition to performing major surgical procedures on people in their eighties, for whom only limited benefits may be possible. People willingly donate money to send small children to the Loma Linda Hospital in California for multiple organ transplants even if the cost-benefit ratio is stratospherically high.

These messy realities constitute a problem for formulary management. Once a medical procedure is approved, inter- 
ference in its application to ever-expanding situations rarely occurs. In the year 2000, for example, Alberta decided to double the rate at which magnetic resonance imaging scans were offered, without any evaluation of the expected costs and concrete health benefits (7). Surgeons who perform expensive procedures on patients who would otherwise die, but who are highly unlikely to benefit, might be acting with compassion and in accordance with the wishes of the patient and/or family, but, if subjected to formulary decision criteria, the intervention might be highly questionable. Similarly, it has proved extremely difficult to predict and control the utilization of many drugs after they have been listed on the formulary. Cost effectiveness estimates that have been established in the scientific literature or by a technological assessment might not be realized in practice (8). The resulting escalation of pharmaceutical costs creates pressures to apply higher standards to new drugs. Again, this might be prudent from the standpoint of resource stewardship, but it may also involve a form of discrimination that warrants close examination.

\section{THE MEASUREMENT DILEMMA}

A well-known issue in health economics involves deciding what gets measured and included in cost effectiveness analyses. The outcome is greatly influenced by these choices, which are based on assumptions about which there might be substantial disagreement among qualified experts. Indeed, decision-makers might not be aware of, let alone understand or articulate, these assumptions.

Formulary decision-making criteria often include utility concepts, the most frequently used being QALYs. Such measures have the advantage of transparency and applicability across disease categories. Nevertheless, they are not value-neutral and do not incorporate all conceivable economic consequences of therapies (9). For example, they may discriminate on the basis of age, because young people have a far greater potential to add quality life-years than do older people. However, one should not assume that formularies adhere rigidly to economic calculations of this type: there is evidence that actual formulary decision-making rarely use concepts such as cost effectiveness ratios in arriving at decisions (10).

The dilemma is twofold: what to measure and include in the calculus, and how to set thresholds. For example, how should one assess the potential to return to work? Should it make a difference if the patient could return to a job that pays $\$ 100,000$ per year, as opposed to one that pays $\$ 15,000$ ? Should retirees automatically be assigned lower priority or, in a public system, should one dismiss this option because they are entitled to treatment by virtue of having paid taxes during their working lives? Formularies are usually sensitive to these dilemmas and often refer to "resumption of normal activities" as the criterion, regardless of whether these involve paid work or leisure pursuits. But if the final decision is justified purely in economic terms the ratio of benefits to costs - then individual circumstances do matter. This would be the case especially in a system that permitted more individualized decisions. Appealing though this may be on the surface, it doubtless adds enormous ethical and economic complexity to decision making and evaluation.

\section{CAN THE CIRCLE BE SQUARED?}

In a perfect world, science, transparency, and prudence would govern drug production, marketing, prescribing and consumption. Formularies exist in an imperfect world fraught with clinical uncertainty, individual circumstances, and financial incentives and pressures. Changing the way formularies are conceived and managed would require major changes in both the provision of health care and the business culture of the pharmaceutical industry. No doubt the current system is not absolutely fair, but perfection is unattainable. Could the system be made more flexible and responsive, while keeping costs affordable?

One commonly advocated approach to changing formulary rules and practices is risk-sharing. The basic idea is that the manufacturer and (in the case of public formularies) the state should share the costs of including new products, and that financial risks and rewards should be based on their impact on actual practices. Calculating the benefits of therapy is not always straightforward and there are a host of confounders involved in evaluating the financial impact of successful interventions. Distributing the risk would appear, at least in theory, to be a potentially promising strategy for allowing greater flexibility in decision-making, particularly where estimates of clinical and cost effectiveness vary widely. It would require manufacturers to incorporate pharmacoeconomic reasoning and estimates into their developmental processes to a greater extent than is now apparently the case (11).

Finally, there is the issue of price. For most new drugs the sunk costs are very high and the marginal costs are quite low. If the cost-benefit ratio is deemed unacceptably high by the formulary decision-making process or the technological assessment, it can be altered by changing the price. This obviously would require a series of coordinated judgments and decisions by both manufacturers and the formulary managers. In theory, a general pharmacoeconomic and pricing framework for pharmaceuticals could guide research and development programs and decision criteria, although here, too, there would inevitably be uncertainty and competing imperatives.

In light of these complexities and uncertainties, a primary public policy objective in the management of statefinanced formularies should be transparency and consistency. The first obligation is fairness, but a fair system can be harsh, ineffective and inefficient. It merely promises equitable entitlements based on need and prospect to benefit, however difficult these may be to estimate. The ultimate goal is optimal drug therapy that achieves the best combination of clinical and economic effect. Achievement of these goals will depend partly on improved technical infrastructure and methods to better account for all costs and benefits, track the impact of decisions over time and model 
the impact of decisions more comprehensively. It is especially important to evaluate whether the values ostensibly guiding formulary decisions are consistently applied.

\section{REFERENCES}

1. Lexchin J. Improving the appropriateness of physician prescribing. Int J Health Serv 1998;28:253-67.

2. Wang EE, Einarson TR, Kellner JD, Conly JM. Antibiotic prescribing for Canadian preschool children: Evidence of overprescribing for viral respiratory infections. Clin Infect Dis 1999;29:155-60.

3. Thomson M, Smith WA. Prescribing benzodiazepines for noninstitutionalized elderly. Can Fam Physician $1995 ; 41: 792-8$

4. Dhalla IA, Anderson GM, Mamdani MM, Bronskill SE, Sykora K, Rochon PA. Inappropriate prescribing before and after nursing home admission. J Am Geriatr Soc 2002;50:995-1000.

5. Burton SL, Randel L, Titlow K, Emanuel EJ. The ethics of Pharmaceutical benefit management. Health Aff (Millwood) 2001;20:150-63.
6. Leon DA, Walt G, Gilson L. Recent advances: International perspectives on health inequalities and policy. BMJ 2001;322:591-4.

7. Alberta Health and Wellness. Government of Alberta News Release - Alberta to lead country in MRI scans. <http://www.gov.ab.ca/acn/200104/10508.html> Version current at November 20, 2002

8. Schneeweiss S, Maclure M, Walker AM, Grootendorst P, Soumerai SB. On the evaluation of drug benefits policy changes with longitudinal claims data: The policy maker's versus the clinician's perspective. Health Policy 2001;55:97-109.

9. Schwappach DL. Resource allocation, social values and the QALY: A review of the debate and empirical evidence. Health Expect 2002;5:210-22.

10. Mauskopf JA, Paul JE, Grant DM, Stergachis A. The role of costconsequence analysis in healthcare decision-making. Pharmacoeconomics 1998;13:277-88.

11. DiMasi JA, Caglarcan E, Wood-Armany M. Emerging role of pharmacoeconomics in the research and development decisionmaking process. Pharmacoeconomics 2001;19:753-66 


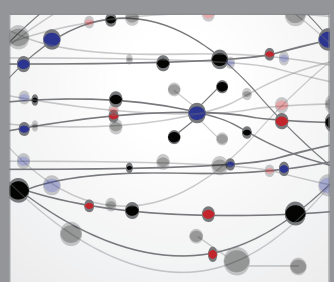

The Scientific World Journal
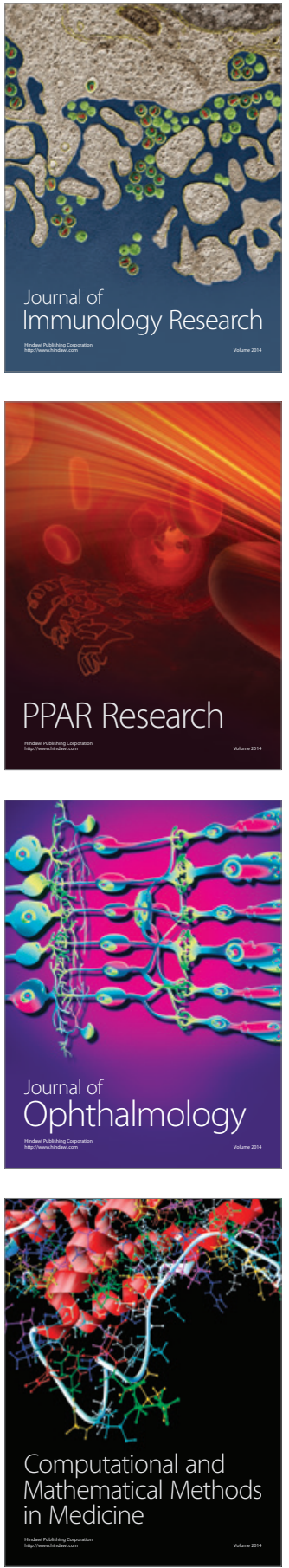

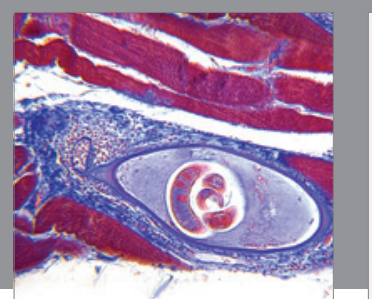

Gastroenterology Research and Practice

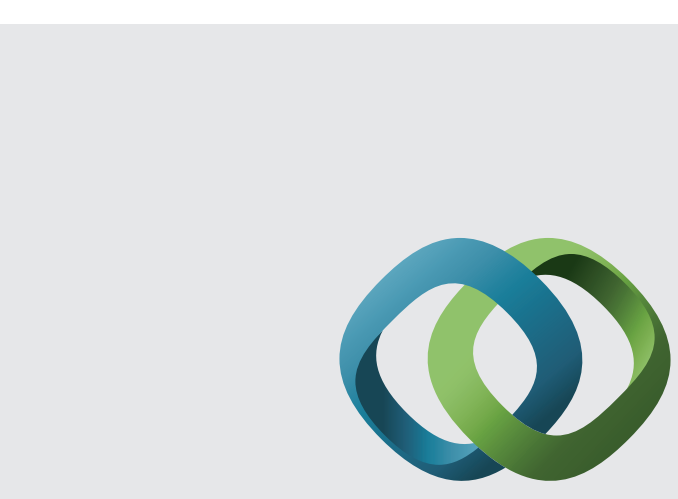

\section{Hindawi}

Submit your manuscripts at

http://www.hindawi.com
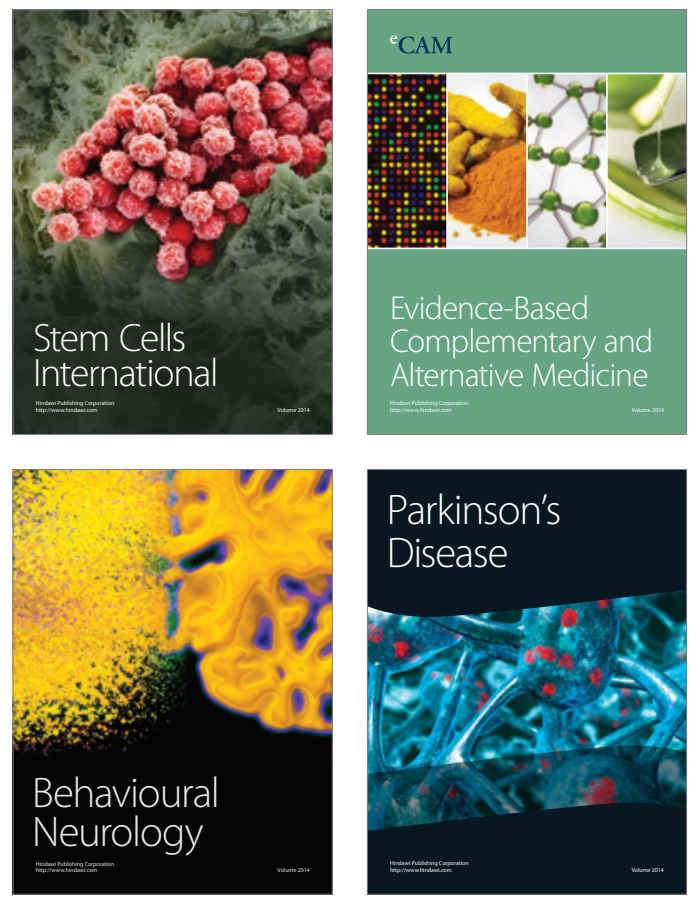
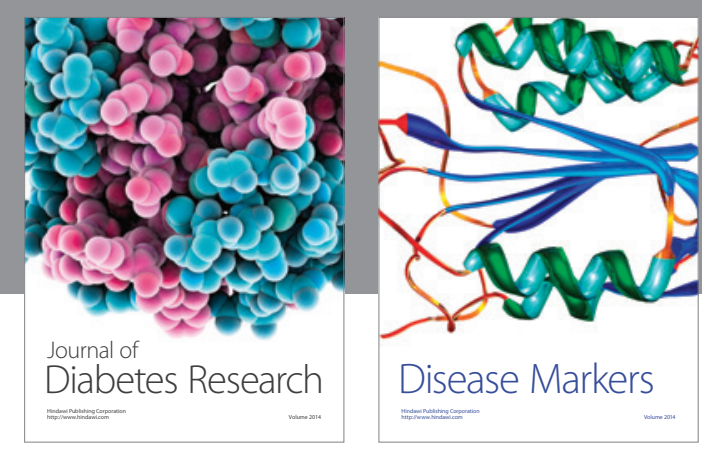

Disease Markers
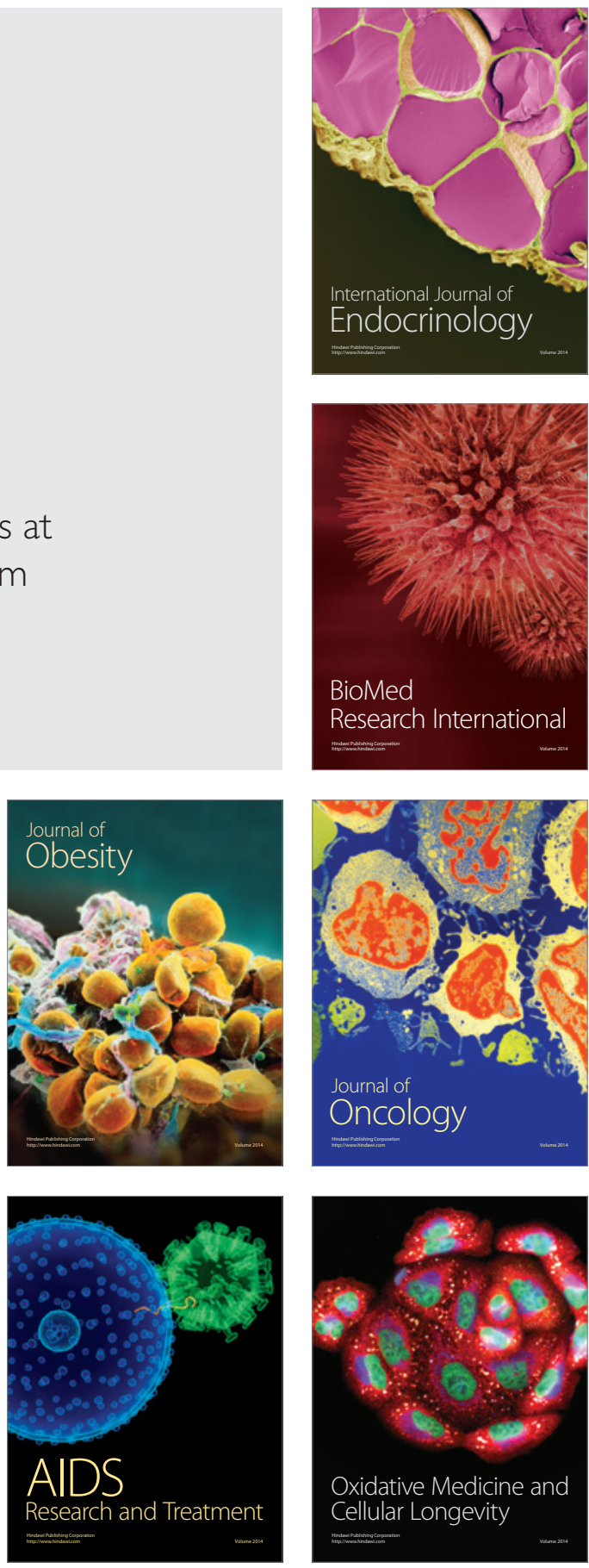